\section{In Vitro Flowering in Regenerated Shoots of Spinach.}

\author{
Jameel M. Al-Khayri, Feng H. Huang, and Teddy E. Morelock \\ Department of Horticulture and Forestry, University of Arkansas, \\ Fayetteville, AR 72701
}

\section{Forrest E. Lane}

Department of Botany, University of Arkansas, Fayetteville, AR 72701

Additional index words. callus, leaf explant, micropropagation, tissue culture, Spinacia oleracea

Spinach (Spinacia oleracea L.) flowers in response to long photoperiods. It is considered to be a dioecious species, but monoecious types also occur (Janick and Stevenson, 1955). Isolated stem tips of spinach seedlings have flowered in response to long days, exhibiting the same photoperiodic reactions as the intact plants (Culafic, 1973). Several plant species have been induced to flower in vitro from shoot-tip explants (Al Wareh et al., 1989; Tang et al., 1983; Tisserat and Galletta, 1988) and nodes (Dickens and van Staden, 1985). The in vitro flowering of shoots derived from callus cultures has also been reported for a few species (Al Wareh et al., 1989; Yoshikawa and Furuya, 1983). Our objective was to establish a system for in vitro flower induction in regenerated spinach shoots.

Modification of a previously described tissue culture method for the regeneration of 'Fall Green' spinach from leaf-derived callus (Al-Khayri et al., 1991) was employed. Leaves from 3-month-old 'High Pack' spinach were surface-sterilized in $70 \%$ ethanol for 30 set and $1 \% \mathrm{NaOCl}(20 \%$ Clorox) for $5 \mathrm{~min}$ and then rinsed three times in sterile distilled water. Callus was induced from 5 $\mathrm{mm}$ leaf disks on MS medium (Murashige and Skoog, 1962) containing (mg.liter $\left.{ }^{-1}\right) 2$ kinetin and 0.5 (2,4-dichlorophenoxy)acetic acid (2,4-D). Shoots were regenerated under a 10-h photoperiod of cool-white fluorescent light $\left(65 \mu \mathrm{mol} \cdot \mathrm{m}^{-2} \cdot \mathrm{s}^{-1}\right)$ at $22 \pm 3 \mathrm{C}$ on $\mathrm{MS}$ medium containing (mg.liter $\left.{ }^{-1}\right) 2$ kinetin, $0.012,4-\mathrm{D}$, and 1 gibberellic acid (GA,). Callus induction and shoot regeneration media were supplemented with $\left(\mathrm{mg} \cdot \mathrm{liter}^{-1}\right) 100$ myo -inositol, 0.4 thiamine $\cdot \mathrm{HCl}, 0.5$ nicotinic acid, 0.5 pyridoxine $\cdot \mathrm{HCl}$, and $3 \%$ $(w / v)$ sucrose. Media were solidified with $0.8 \%$ agar (agar-agar/gum agar; Sigma Chemical Co., St. Louis). The medium pH was adjusted to 5.8 before being autoclaved at $121 \mathrm{C}$ and $103 \mathrm{kPa}$ for $15 \mathrm{~min}$.

After 8 to 12 weeks, regenerated shoots

Received for publication 21 Feb. 1991. Published with approval of the Director of Arkansas Agricultural Experiment Station. The cost of publishing this paper was defrayed in part by the payment of page charges. Under postal regulations, this paper therefore must be hereby marked advertisement solely to indicate this fact.
(Fig. 1A) were subcultured onto identical fresh medium for further multiplication. Shoots 1 to $3 \mathrm{~cm}$ tall were separated and transferred to Magenta GA7 vessels (Magenta, Chicago) (six shoots per vessel) containing $50 \mathrm{ml}$ hormone-free MS medium with the same supplements but solidified with $0.8 \%$ Phytagel (Sigma). Twenty culture vessels were maintained under long-day (14-h) photoperiods to encourage flowering. As a control, five vessels were maintained in short-day (10-h) photoperiods.. After 12 weeks in long days, the shoots were scored for flowering.

Shoots on hormone-free medium flowered when subjected to long days. Although not all shoots responded during the span of the experiment, $89 \%$ produced flower stalks. The shoots that failed to flower seemed less vigorous than flowering shoots. All shoots that were maintained under short days remained vegetative (Fig. 1B).

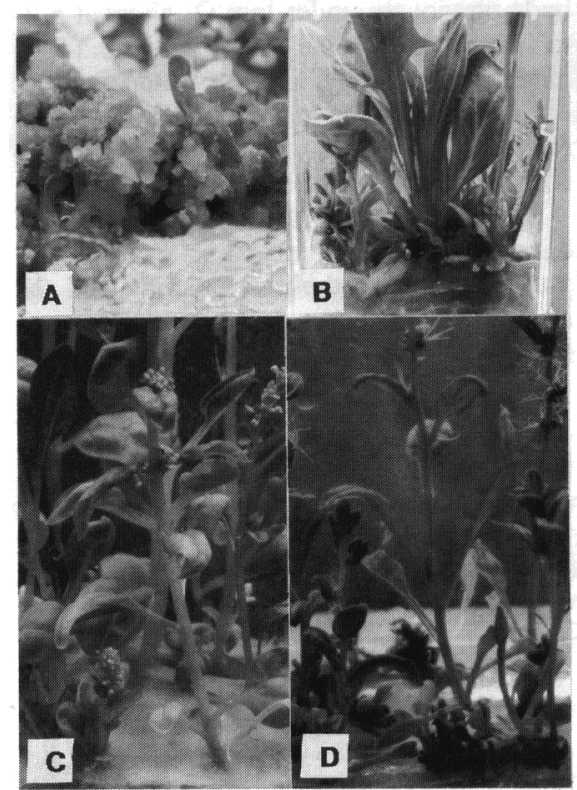

Fig. 1. In vitro flowering of spinach. (A) In vitro shoots arising from spinach callus; (B) plantlets maintained in short days persisted in vegetative stage; (C) plantlets stimulated to enter reproductive stage by exposure to long days on a hormone-free medium, male flowers are visible; (D) regenerated shoot from female explantdonor plant bearing female flowers.
The results indicate that the flowering stimulus occurred in response to daylength, as in plants grown in vivo or in vitro from shoot tips (Culafic, 1973). Comparably, node explants of soybean, a short-day plant, have been induced to flower by subjecting the cultures to short days on a hormone-free medium (Dickens and Van Staden, 1985). In vitro flowering- of the regenerated spinach shoots suggests a functional flowering mechanism triggered by the long-day exposure. Male plant-derived callus gave rise to shoots that eventually produced male flowers (Fig. 1C). Female plant-derived callus regenerated shoots that bore female flowers (Fig. 1D).

Rooting was induced regardless of day-length; $75 \%$ and $73 \%$ of the shoots produced roots in long days and short days, respectively. Among the shoots that flowered, $10 \%$ did not root, suggesting that the flowering stimulus may be produced in the shoot region of the plant without involvement of the roots.

Many investigators incorporate growth regulators in the flowering medium to encourage growth and flower initiation. Our system used a hormone-free medium that allows study of the influence of exogenous growth regulators on flower development. The influence of growth regulators on sex expression may be determined more easily with shoots arising from a single explant excised from a male or female plant using the system described here. Eventually, hormonal manipulation of regenerates derived from a single plant may enable spinach breeders to achieve "self-pollination" and obtain seeds, thereby conserving the genotype of selected elite plants.

\section{Literature Cited}

Al-Khayri J.M., F.H. Huang, and T.E. Morelock. 1991. Regeneration of spinach from leaf callus. HortScience 26:913-914.

Al Wareh, H., N.L. Trolinder, and J.R. Goodin. 1989. In vitro flowering of Potato. HortScience 24:827-829.

Culafic, L. 1973. Induction of flowering of isolated Spinacia oleracea L. buds in sterile culhue. Bul. Inst. Jardin Bot. Univ., Belgrade 8:5356.

Dickens, C.W.S. and J. van Staden. 1985. In vitro flowering and fruiting of soybean explants. J. Plant Physiol. 120:83-66.

Janick, J. and E.C. Stevenson. 1955. Genetics of the monoecious character in spinach. Genetics 40:429-437.

Murashige, T. and F. Skoog. 1962. A revised medium for rapid growth and bioassays with tobacco tissue cultures. Physiol. Plant. 15:473497.

Tang, A.F., M. Cappadocia, and D. Byrne. 1983. In vitro flowering in cassava (Manihot esculenta Crantz). Plant Cell Tissue Organ Cult. 2:199-206.

Tisserat, B. and P.D. Galletta. 1988. In vitro flowering in Amaranthus. HortScience 23:210212

Yoshikawa, T. and T. Furuya. 1983. Regeneration and in vitro of plants derived from callus cultures of opium poppy (Papaver somniferum). Experientia 39:1031-1033. 